\title{
[RETRACTED ARTICLE] Association between periodontal disease and subclinical atherosclerosis: the ELSA-Brasil study
}

\section{[ARTI GO RETRATADO] Associação entre doença periodontal e aterosclerose subclínica: estudo ELSA-Brasil}

\author{
Rafaela das Mercês Batista(I ); Elizabeth Pimentel Rosetti(I); Eliana Zandonade( I I); \\ Leonard Hermann Roelke(I); Mario Vianna Vettore(I I I); Adauto Emmerich \\ Oliveira(I) \\ (I) Centro de Ciências da Saúde, Universidade Federal do Espírito Santo, Vitória, Brasil \\ (II) Centro Universitário de Vila Velha, Vila Velha, Brasil \\ (III) Instituto de Estudos em Saúde Coletiva, Universidade Federal do Rio de Janeiro, Rio de \\ Janeiro, Brasil
}

To the Editor: We wish to retract our article Association Between Periodontal Disease and Subclinical Atherosclerosis: The ELSA-Brasil Study, published in CSP in May 2012. Contrary to the article's title and methodology as described, the data did not come from the ELSA-Brasil study [Brazilian Longitudinal Study of Adult Health], but were collected independently and with different objectives. Thus, the article is not a supplementary study to the ELSA-Brasil study and should not be referred to as such. The point in common between this study and ELSABrasil is that the study population in both consists of employees from a public university in the State of Espírito Santo, Brazil. However the points and methodology for measuring the intimamedia thickness (IMT) were different from those adopted by ELSA-Brasil. The authors apologize to the Executive Board of the ELSA-Brasil study and to the Editor and readers of Cadernos de Saúde Pública for this error.

R. M. Batista, E. P. Rosetti, E. Zandonade, L. H. Roelke, M. V. Vettore, and A. O. Emmerich 


\title{
Association between periodontal disease and subclinical atherosclerosis: the ELSA-Brasil study
}

\author{
Associação entre doença periodontal e aterosclerose \\ subclínica: Estudo ELSA-Brasil
}

1 Centro de Ciências da Saúde, Universidade Federal do Espírito Santo, Vitória, Brasil.

2 Centro Universitário de Vila Velha, Vila Velha, Brasil. 3 Instituto de Estudos em Saúde Coletiva, Universidade Federal do Rio de Janeiro, Rio de Janeiro, Brasil.

Correspondence

R. M. Batista

Programa de Pós-graduação em Saúde Coletiva, Centro de Ciências da Saúde, Universidade Federal do Espírito Santo.

Av. Resplendor 563, sala 305, Vila Velha, ES 29101-500,

Brasil.

rafinhambatista@hotmail.con
$P$ faela Mercês Batista 1

lizabe $\backslash$ Pim itel Rosetti 1

E.." Zandonade 2

Leona. Hermann Roelke 1

Mario Vianna Vettore 3

A au. Emmerich Oliveira 1

\section{Introduction}

Atherosclerosis is one of the leading causes of adult mortality and morbidity in Latin America 1. Due to its different etiologies, many underlying causes remain unknown 2 .

Studies have suggested that periodontal disease is associated with the early development of atherosclerotic lesions in the carotid artery 3,4,5,6. Periodontal disease is a chronic multifactorial immune disease that occurs in response to periodontopathogenic antigens. The condition begins with inflammation of the tissues surrounding and supporting the teeth and can progress until involving the entire periodontium, including the alveolar bone, cementum, and periodontal ligament, leading to irreversible loss of the periodontium and eventually tooth loss in the more advanced stages 7 .

The association between periodontal disease and atherosclerotic cardiovascular disease has received considerable attention 8,9 , but these studies' findings are not consistent. Some studies report that periodontal disease, through an inflammatory process, can cause infection of the vascular endothelium and contribute to the occurrence of atherosclerosis, increasing the risk of myocardial ischemia and infarction, always preceded by thromboembolic events 10 . In addition to this hypothesis, it has been suggested that periodontal microorganisms can induce or accelerate atherosclerosis through different 
mechanisms, for example: favoring the local increase in lymphocytes, macrophages, and production of tissue growth factors; local release of endotoxin (lipopolysaccharides), and molecular mimicry between microbial and human heat shock protein 60 , inducing an autoimmune reaction. In addition, the systemic increase in cytokines with activation of inflammatory markers and stimulation of pro-coagulants can lead to thrombosis and acute ischemia, besides inducing changes in lipoproteins, resulting in pre-atherosclerotic conditions 11.

Mild to moderate periodontal disease affects $30-50 \%$ of the adult population, while the severe generalized form affects $5-15 \%$ of adults in the United States 12 . The multifactorial etiology of periodontal disease includes both specific subgingival bacteria and individual factors such as age, race, and gender, and systemic factors like smoking, diabetes, osteoporosis, and stress. In addition, poor diet, low socioeconomic status, and limited access to health services have been associated with its occurrence 12 .

Among the risk factors presented for periodontal disease, age, smoking, and mellitus are generally considered po $^{+}$atial con. founding variables in studies on as ciations in periodontal disease 10 .

Inflammation is a comms characte tir both in atherosclerosis and $r$ ilodor disease, and thus a common mediat of the etwo $c$ aditions 13,14 . There is no co sensu oncerr ig the possible influence of $\mathrm{p}$ codontal $\mathrm{a}_{\mathrm{s}}$ on the thickness of the carot ${ }^{\prime}$ a ry intima-media complex (IMC). The majuity of su. 'ies that have evaluated this association present ethodological limitations, lik omall sample size, lack of control of confoundi g variables, resence of bias, and discrepancies the case d inition for periodontal disease 15,16,. limi $^{+} \mathrm{g}$ the internal validity and $\mathrm{pr}$ tially jeoparuzing the conclusions.

The najor the literature reviewed in the studies $8,1 \quad u$ ports a modest association between $r$ - idonta isease and atherosclerosis. However, rack stand dization of measures and definition $\mathrm{I}_{\mathrm{P}}$ - nontal disease, as well as the potentia confounding factors common to both conditiv hinder interpretation of the results 18 .

A tter understanding of the relationship between periodontal disease and the risks of ubclinical atherosclerosis motivated the current study, the objective of which was to investigate the relationship between clinical parameters of periodontal disease and thickening of the carotid IMC, used as a proxy for diagnosing subclinical vascular disease in adults.

\section{Methods}

\section{Participants}

A cross-sectional study was co.'11 1 cted am ng participants in the Brazilion Innglı. 'nal cudy ofAdult Health (the ELSA srasil). The EL, -Brasil study is a multicenter ( hort study nsisting of 15 thousand employees rom public astitutions of higher learning res ch in e Northeast, South, and Sout east rions or Brazil. The purpose of the st dy is to in igate the incidence and risk fac ${ }^{+} \sim r$ chronic diseases, in particular cardiovas alar dis es and diabetes. The supplemental oral health dy for ELSA-Brasil was based $n$ da collected in the ELSA project in the $\mathrm{Sta}^{+}$of Espí pon ric amination and carotid ultrasound.

This "Idy's target population consisted of male and to ale active and retired employees from 74 years of age, from the ELSA project/ s' to Santo. The sample universe consisted or e 497 participants in the ELSA project that wer reated and had undergone ultrasound of the common carotid artery by a single examiner. Providing for possible losses, all were invited to participate in the study. The only exclusion criterion was the use of total upper and lower dental prostheses.

The final sample consisted of 220 participants (78 with increased IMC thickness and 142 with normal IMC). This sample size allowed detecting an expected 25\% (estimated) difference between the proportion of periodontal disease in the sample with normal carotid IMC and in the sample with altered carotid IMC, with a minimum power of $80 \%$ and $5 \%$ significance.

An intra-examiner clinical calibration study for the periodontal examination was conducted previously. A single examiner responsible for examination in the principal study performed the intra-examiner calibration, under the supervision of the external observer, in the same location and under the same conditions of lighting and instrumentation, with employees from the same age bracket as the study participants. Seventeen patients were examined, with 48-hour intervals between examinations. The clinical parameters considered for calibration were: probing pocket depth (PPD) and clinical attachment level (CAL) of teeth 16, 11, 27, 31, 37, and 46, with a total of 96 measurements performed (48 measurements at two moments). Reliability between measurements was tested using the intra-class correlation coefficient (ICC) and comparison of the means with the matched t test. Of 48 comparisons, 41 showed statistically significant correlations, of which 5 with ICC $>0.80$ and 3 with ICC 
from 0.50 to 0.80 . The analysis did not include three comparisons, because there was no variation in the measurements. In the comparison of means, 47 of the 48 comparisons were statistically significant.

\section{Periodontal clinical examination}

Participants were submitted to periodontal examination by a single calibrated examiner who was blind to the carotid ultrasound data.

Periodontal clinical measurements used in the study were: plaque index (PI) 19, gingival bleeding index (GBI) 19, PPD, and CAL. The PI and GBI parameters were measured dichotomously as the presence or absence of bacterial plaque and bleeding after periodontal probing.

For PPD, CAL, GBI, and PI, six measurements were taken per tooth, corresponding to the mesiobuccal, midbuccal, distobuccal, mesiolingual, midlingual, and distolingual surfaces. All the clinical measurements were taken in all the teeth, except for the third molars.

PPD measurements were recorded in millimeters from the free gingival margin to the bottom of the gingival sulcus or periodontal pocket. In the CAL measurements, the cementumdentin junction and gingival level were used as reference points. PPD and CAL measurements were recorded with a North Carolina model periodontal probe (Hu-Friedy, Chicago, USA), with 1 -millimeter markings over a total of $15 \mathrm{~mm}$ an a tip with $0.35 \mathrm{~mm}$ diameter.

When the gingival margin or cementum tin junction was located between two ma.ks on the periodontal probe, the value from tho deepest marking was recorded. In addition $\sigma$ the periodontal measurements, the numb of natura teeth was also recorded. All measur tents were taken in a single sitting.

\section{Ultrasound examination}

The arterial wall consj af three yers: the intima, a thin endothe' al laye that bo lers on the blood-filled lumer the ad ent the external layer bordering on s rounding tissue, and the media, a 1 yer betv. $n$ these internal and external lay Due to tho easily discernible borders bf veer. 'e lumen and the intima and between the media adventitia, the intima and $\mathrm{r}$ dia are generally evaluated together, whi prov es the measurement of the IMC thic ess

Pros sion atherosclerotic disease is frequ. tly acc janied by a visible thickening of the and the presence of fibrotic or calcified p) ${ }_{1}$ ues 20 .
Measuring the carotid artery IMC thickness is a way of evaluating one of the most important indicators of cardiovascular disease in patients. Its use is based on the possibility of predicting the outcomes of future cardiovascular events with a non-invasive technique, namely ultrasound (US), providing a diagnostic gain based on $\mathrm{t}^{\mathrm{Y}}$ importance of IMC thickening as a risk factor cardiovascular disease 20.

IMC thickness was measured bilater nex to the carotid sinus at the base of the $\mathrm{n}$ ck, u Toshiba Ultrasound Aplio XG (Mode' „SA, 790 A, Toshiba, Barueri, Brazil). The test y s. orformed by a researcher who was blind to ne perlu ntal parameters and other patient characteristics.

\section{Comparison groups}

There is still much disagreemv on which IMC thickness offers the result for thodological standardization. Starm - ation of a protocol to measure IMC hr ges would facilitate the comparison of result rom studies using this technique 20 .

Accord the consensus statement of the Americ Sociel, Echocardiography on the use or arotid ultra und to identify subclinical vascular ease, th sample's $75^{\text {th }}$ percentile corrf ponds to L. vo des adopted as possible future sk of $r$ diovasualar disease 20.

$\mathrm{T}^{\prime}$ s stud used the value corresponding to th ample $75^{\text {th }}$ percentile as altered carotid IMC $\mathrm{L} \quad 1$ ess, which varied from $0.95 \mathrm{~mm}$ in the right common carotid artery to $0.98 \mathrm{~mm}$ in the ft common carotid artery. Thus, participants Wh. right common carotid artery $\geq 0.95 \mathrm{~mm}$ and left common carotid artery $\geq 0.98 \mathrm{~mm}$ were defined as having altered carotid IMC.

\section{Covariables}

The sociodemographic characteristics were collected through a structured interview conducted by trained interviewers and included: age, gender, marital status, self-reported race/skin color, schooling, family income, smoking, and self-reported hypertension, diabetes, and insulin use. The anthropometric characteristic evaluated by the study was body mass index $\left(\mathrm{BMI}=\mathrm{kg} / \mathrm{m}^{2}\right)$, or weight $(\mathrm{kg})$ divided by height squared $\left(\mathrm{m}^{2}\right)$. The equipment used to obtain these measurements included a stadiometer accurate to $0.1 \mathrm{~cm}$, electronic scales calibrated in grams (Toledo 200kg; Toledo do Brasil Indústria de Balanças Ltda., São Bernardo do Campo, Brazil), anthropometric tape measure, $150 \mathrm{~cm}$ - Mabbis, Gulick model (CARDIOMED, Curitiba, Brazil), 20kg test weight - total $80 \mathrm{~kg}$, mobile footrest with height on $8 \mathrm{~cm}$ 
plane, and $1.20 \times 0.50 \mathrm{~cm}$ mirror. BMI was classified according to the World Health Organization (WHO) classification 21.

Periodontal clinical parameters and definition of periodontal disease

All the clinical parameters, PI, GBI, PPD, and CAL, were computed for each study subject and later for each group (normal and altered carotid IMC thickness). Clinical parameters analyzed by the study were number and frequency of sites with PPD and CAL $\geq 3 \mathrm{~mm}, \geq 4 \mathrm{~mm}, \geq 5 \mathrm{~mm}$, and $\geq 6 \mathrm{~mm}$.

Thirteen different definitions of periodontal disease were used according to the literature 12 , $15,22,23,24,25,26,27,28,29,30,31,32$, plus five more definitions. Definition 1: $10 \%$ or more sites with PPD $\geq$ $4 \mathrm{~mm}$ and $\mathrm{CAL} \geq 4 \mathrm{~mm}$; definition $2: 10 \%$ or more sites with PPD $\geq 4 \mathrm{~mm}$ and CAL $\geq 4 \mathrm{~mm}$ and GBI $\geq 10 \%$; definition 3: $20 \%$ or more sites with CAL $\geq 3 \mathrm{~mm}$; definition $4: 20 \%$ or more sites with CAL $\geq 4 \mathrm{~mm}$; and definition 5: $10 \%$ or more sites with CAL $\geq 4 \mathrm{~mm}$.

\section{Statistical analysis}

Comparisons between IMC groups re performed with the chi-square te , Fisher's ar test, Mann-Whitney test, an $r$ test. orrelation between the periodontal cli al po ameter and carotid artery IMC thickne was uated the Spearman correlation $c$ efficient. St logistic regression was perfo $\mathrm{a}$ +o test the association between different a finition f periodontal disease and altered morotid IMC th. kness through odds ratios $(\mathrm{C}$, with $95 \%$ confidence intervals (95\%CI). Mul variate ana es were then used to adjust covari: les. All ana ses used SPSS, version 18.0 (SPSS '., Ch' ago, USA). Statistical signifi was set at $0.05(\mathrm{p} \leq 0.05)$.

Research tt is issues

Partı pants ere required to sign a prior inform a c n form. The project was approved hy ae Institutional Review Board of the Federal し. rersity in Espírito Santo (Universidade Federal Espírito Santo; protocol no. 145/08).

\section{Results}

The sample consisted of 220 individuals among the 497 participants in the ELSA-ES project. It was not possible to contact 160 participants (32.1\%).

Of the 337 individuals that were invited, 61 (18.1\%) refused to participate. Of the 276 that agreed, 45 (16\%) failed to appear fo ne ex aination and $11(4.34 \%)$ were excludea ause they were using total upper and lower ac ${ }^{+}$l prostheses (Figure 1).

There were proportionalı nore fem es among the group that amoned to arti pate (58.2\%). $65.8 \%$ of the stu $y$ sample were arried. White skin color/race vas the me common (45.4\%), followed by bro n race (pal o) (33.5\%). Table 1 shows the p ticipa 'c' soc' demographic characteristic

Table 2 sh ws the sou demographic characteristics 1 RMI according to IMC thickness (alter d versu ormal). Mean age and the proportion of male in iduals and those with diabe s, hy ertension, and overweight/obesity wer statisti in ioher in the group with altered IMc ' $m o$ ' ng did not differ statistically between groups (I 0.5604).

Table 3 apares number of teeth and periodun rameters between groups. Mean numr teeth present, number of sites with $\mathrm{CAL} \geq$ 31 n, $\mathrm{CAL} \geq 4 \mathrm{~mm}, \mathrm{CAL} \geq 5 \mathrm{~mm}$, and $\mathrm{CAL} \geq 6 \mathrm{~mm}$, and equency of sites with CAL $\geq 4 \mathrm{~mm}, \mathrm{CAL} \geq$ $5 \mathrm{~mm}$, and $\mathrm{CAL} \geq 6 \mathrm{~mm}$ and $\mathrm{PPD} \geq 4 \mathrm{~mm}$ were statistically higher in the group with altered IMC thickness as compared to the group with normal IMC. Associations were observed between periodontal clinical parameters and carotid IMC thickness, based on analyses of correlations. Right carotid artery IMC thickening was correlated with $\mathrm{PPD} \geq 5 \mathrm{~mm}$ and $\mathrm{CAL} \geq 5 \mathrm{~mm}$ and $\mathrm{CAL} \geq$ $6 \mathrm{~mm}(\mathrm{p}<0.05)$, while left carotid artery IMC thickening was associated with $\mathrm{PPD} \geq 4 \mathrm{~mm}$, $\mathrm{PPD} \geq 5 \mathrm{~mm}$, and $\mathrm{CAL} \geq 5 \mathrm{~mm}$ and $\mathrm{CAL} \geq 6 \mathrm{~mm}$ $(\mathrm{p}<0.05)$ (Table 4).

Table 5 shows the crude and adjusted associations between different definitions of periodontal disease and altered carotid IMC thickness.

Among the 18 definitions of periodontal disease, seven showed a positive unadjusted association between periodontal disease and altered carotid IMC thickness. In the multivariate analysis, which included the confounding variables, only definition 5 of periodontal disease remained associated with the outcome. The odds of detecting altered carotid IMC thickness were 2.56 times higher in those with at least $10 \%$ of sites with $\mathrm{CAL} \geq 4 \mathrm{~mm}$ (95\%CI: 1.12-5.88).

Table 6 shows the results of multivariate analysis between the variables age, gender, hypertension, diabetes, BMI, periodontal disease, and altered carotid IMC thickness. In the final logistic regression model, in addition to periodontal disease (definition 5), only age remained associated with altered carotid IMC thickness $(\mathrm{OR}=1.04$; 95\%CI: 1.01-1.08). 
Flow chart for screening participants.

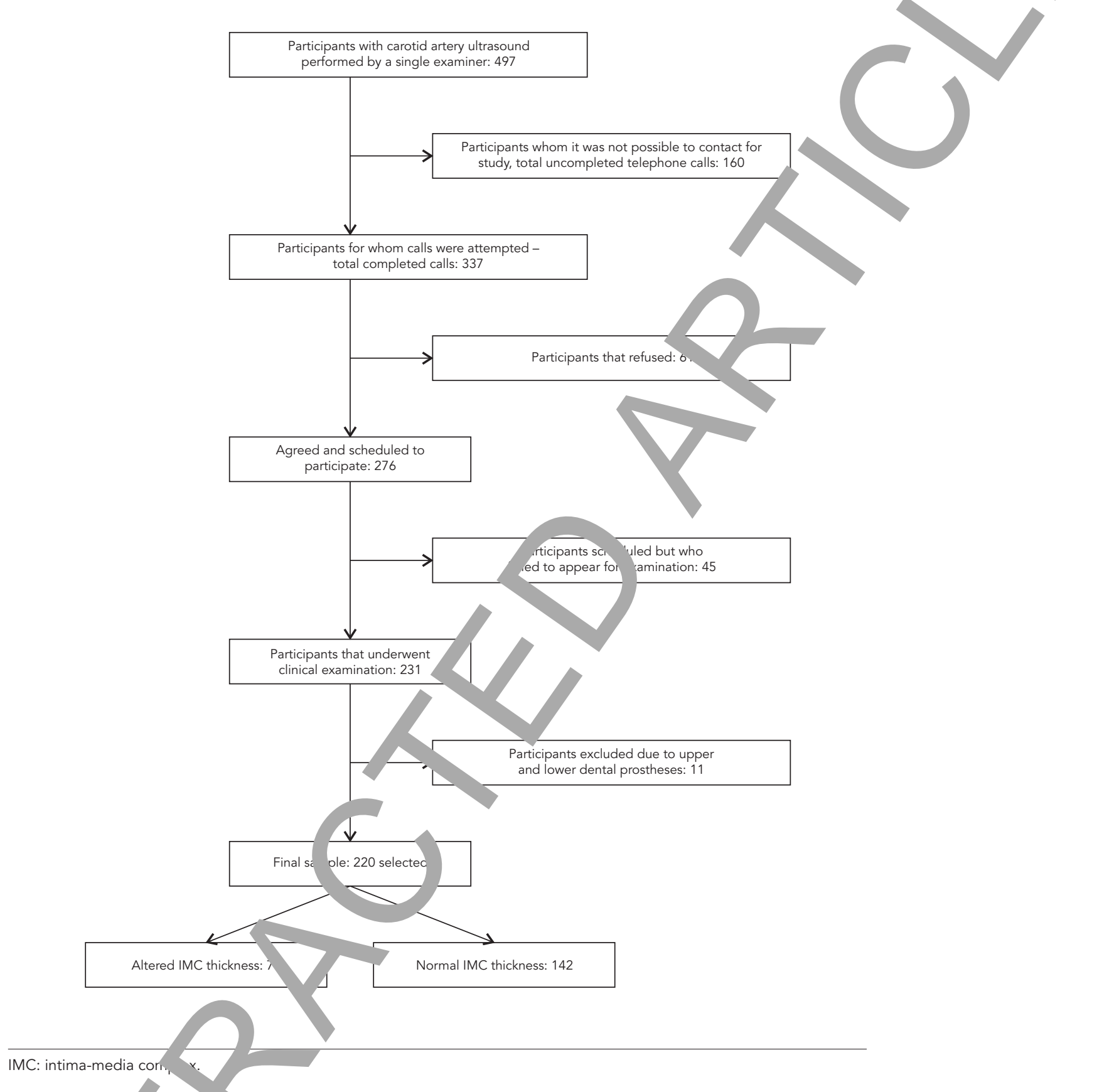

\section{Discussic}

In this udy, individuals with normal carotid IMC thic' 'ess h? more teeth present, and tooth loss was alis ally hir er in individuals with altered IMC th. ness, orroborating another study 16 sric ing tha evalence of carotid plaques increa ubstantially with increased tooth loss; th larges difference was observed between individuals that lost 10 to 19 teeth compared to those that lost zero to nine teeth. According to the authors, edentulism or increased tooth loss was more likely due to sequelae of periodontal disease 16.

Various clinical parameters of periodontal disease, especially those related to CAL, were statistically correlated with bilateral carotid IMC thickness. In addition, these parameters were 
Participants' characteristics: variables and covariables of the 220 adults examined in the study.

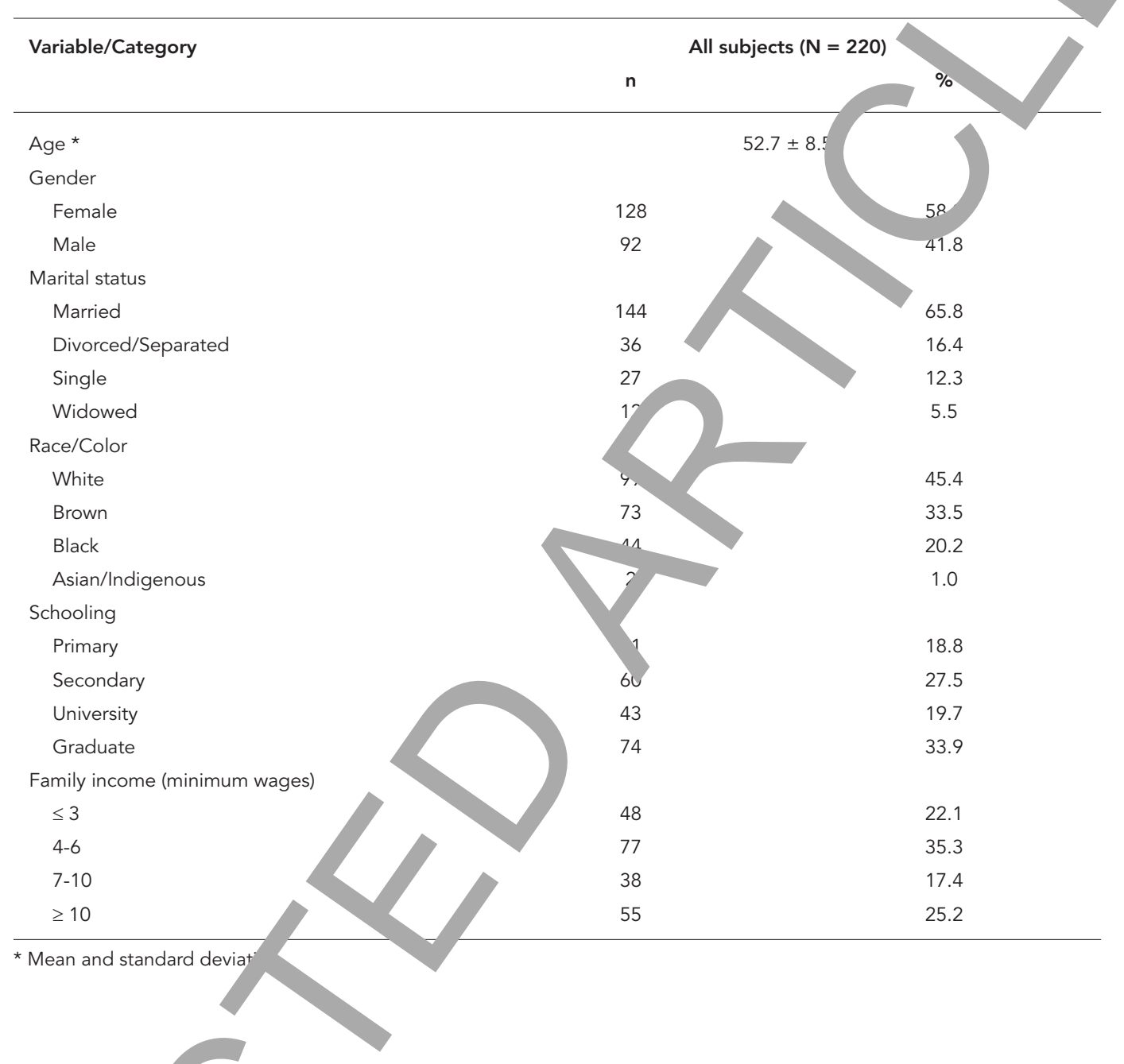

more frequer in individ 's with altered mean carotid IMC 1 ickness. Al 1 ough 18 definitions of periodontal a ase w e used, only one confirmed hypothesis of an association between periode tal ur and subclinical atherosclerosis. Inc id als with $10 \%$ or more sites with $C^{\wedge} \geq 4 \mathrm{~mm}$ howed higher odds of carotid IMC thick ning.

f in . tudy by Demmer et al. 4 , measures of everity and extent of CAL and higher tooth lo were associated with chronic markers such as alt d IMC thickness, while the same was not observed with PPD.

Findings from studies on the association between periodontal disease and atherosclerosis are highly dependent on how periodontal disease is defined. There is no consensus on the standard definition for diagnosing periodontal disease in these studies. In addition, other limitations were observed, such as indirect, inadequate, or incomplete measurements of periodontal disease, as well as self-reported periodontal disease 33 . This scenario produces inconsistent findings, leading researchers to question both the magnitude and significance of the observed associations 8,17.

Although there are studies on the association between periodontal disease and cardiovascular diseases, little research has specifically addressed the possible systemic effects of the systemic dissemination of oral microorganisms in humans 4,13 .

In a longitudinal study that defined bacterial exposure using immunoglobulin G (IgG) serum antibodies, the odds of carotid atherosclerosis were higher in subjects with elevated levels of oral microorganisms. This association was independent of smoking, suggesting that the latter was not a confounding or effect-modifying variable 14. Likewise, the present study found no association between smoking and subclinical atherosclerosis. 
Risk fact ors of the 220 adults according to carotid intima-media complex (IMC) group.

\begin{tabular}{|c|c|c|c|c|c|c|c|}
\hline \multirow[t]{2}{*}{ Risk factors/Category } & \multirow[t]{2}{*}{ Total $(\mathrm{N}=\mathbf{2 2 0})$} & \multicolumn{2}{|c|}{ Normal IMC } & \multicolumn{2}{|c|}{ Altered IMC } & \multirow[t]{2}{*}{$\%$} & \multirow[t]{2}{*}{$p-v a^{\prime}=$} \\
\hline & & $\%$ & $n=142$ & $\%$ & $\mathrm{n}=78$ & & \\
\hline Age * & $52.7 \pm 8.5$ & & 8.2 & & & & 0.0001 ** \\
\hline \multicolumn{8}{|l|}{ Gender } \\
\hline Female & 128 & 58.2 & 91 & 64.1 & 37 & 17.4 & 0.0166 *** \\
\hline Male & 92 & 41.8 & 51 & 35.9 & 41 & 52.6 & \\
\hline \multicolumn{8}{|l|}{ Smoking } \\
\hline Smoker & 18 & 8.3 & 12 & 8.5 & & 7.8 & 0.5604 *** \\
\hline Former smoker & 72 & 33.0 & 43 & 30.5 & 29 & 37.7 & \\
\hline Never smoked & 128 & 58.7 & 86 & 61.0 & 42 & 54.5 & \\
\hline \multicolumn{8}{|l|}{ Hypertension } \\
\hline No & 134 & 61.5 & 96 & & 38 & 49.4 & $0.0066 * \star \star$ \\
\hline Yes & 84 & 38.5 & 45 & 31.9 & 39 & 50.6 & \\
\hline \multicolumn{8}{|l|}{ Diabetes } \\
\hline No & 192 & 88.1 & 129 & & 63 & 81.8 & 0.0352 *** \\
\hline Yes & 26 & 11.9 & 12 & & 14 & 18.2 & \\
\hline \multicolumn{8}{|l|}{ Insulin } \\
\hline No & 214 & 98.2 & 140 & 99.3 & 74 & 96.1 & 0.0938 *** \\
\hline Yes & 4 & 1.8 & 1 & 0.7 & 3 & 3.9 & \\
\hline \multicolumn{8}{|l|}{ BMI } \\
\hline Underweight & 6 & 2.7 & & 4.2 & 0 & 0.0 & 0.0211 *** \\
\hline Normal weight & 74 & 33.6 & & 35.9 & 23 & 29.5 & \\
\hline Overweight & 98 & 44.5 & 62 & 43.7 & 36 & 46.2 & \\
\hline Obesity & 38 & 17.3 & & 16.2 & 15 & 19.2 & \\
\hline Morbid obesity & 4 & 1.8 & 0 & 0.0 & 4 & 5.1 & \\
\hline
\end{tabular}

BMI: body mass index.

* Mean and standard deviation;

${ }^{* *}$ t test;

$\star \star \star *$ Chi-square test.

Recent studies found modest : sociations between advanced periodontal disease $d$ too $^{+}$ loss and carotid IMC thick $f^{-} \cdot{ }^{\prime}$ in developed countries 4,6. Other studies re cu tod in individuals with associated co. it ns such as chronic kidney disease - kidney ansplant 34 .

The observed a ociat on bet en severe periodontal disear and ir ea carotid IMC thicknesshadbeen 1 or ${ }^{+}$din a previous study 15 . Severe period ital dise. was associated with increased $\mathrm{r}$ an IMC thic ess (OR = 1.312; 95\%CI: $1 . \Gamma^{\circ}-1.6 \mathrm{~b}$ but this association did not remain $a$ fter the adju. d analysis.

$\mathrm{Se}$ re periodontal disease was also associated vith su clinical atherosclerosis (IMC thicknes $0.9 \mathrm{~mm}$ ) i systemically healthy young individu and ith age $\leq 40$ years 5 . Even using ait. ent ag. ackets, both the previous study and tudy found an association, so age is an in ortant confounding variable 16 . Another dif- ference that appeared when comparing our findings with those of previous studies relates to the cutoff between altered and normal IMC thickness 5 . It is difficult to compare studies that use the altered versus normal classification of IMC thickness, because there is no consensus on the cutoff to define the altered group, since this is done with the $75^{\text {th }}$ percentile of IMC thickness for the sample. Thus, the classification of altered carotid IMC thickness depends on the distribution of measurements of IMC thickness in each study.

A limitation of the current study was its crosssectional design, which does not allow inferences on causality. Importantly, only one of the 18 definitions of periodontal disease was associated with carotid IMC thickening after multivariate analysis, and in this measurement only CAL was considered. Although there is no clinical parameter that indicates activity of periodontal disease, 
Table 3

Periodontal clinical parameters according to normal versus altered carotid intima-media complex (IMC).

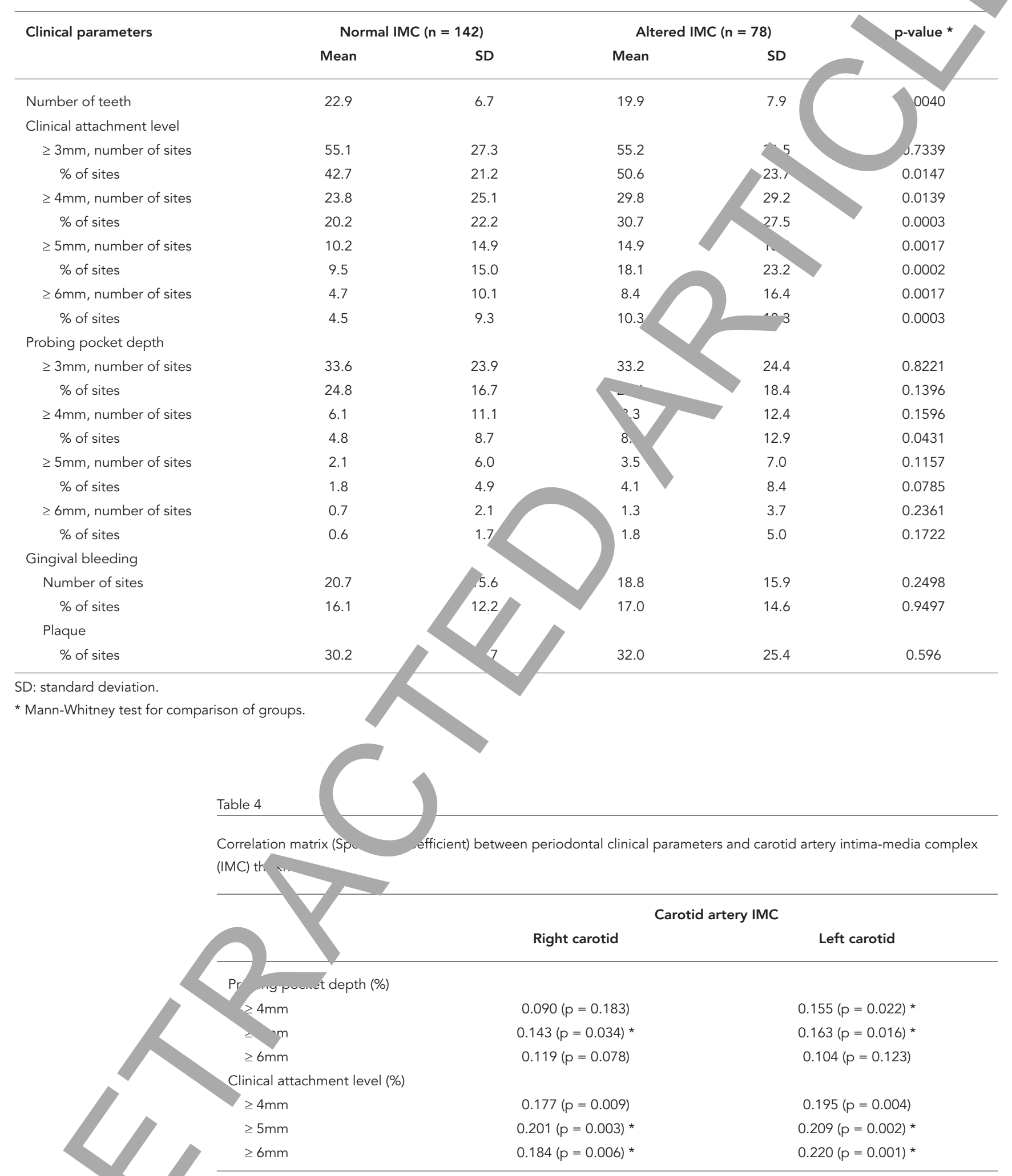

* $p<0.05$. 
Crude and adjusted odds ratios (OR) and respective $95 \%$ confidence intervals (95\% $\mathrm{Cl}$ ) for relationship between altered carotid intima-media compl and periodontal disease, age, gender, hypertension, diabetes, and body mass index (BMI).

\begin{tabular}{|c|c|c|}
\hline Definition of periodontal disease & Crude OR $(95 \% \mathrm{Cl})$ & $\mathrm{R} / \% \mathrm{C}$ \\
\hline \multicolumn{3}{|l|}{ Models from literature } \\
\hline$>1$ site with PPD $\geq 4 \mathrm{~mm}$ and $\geq 50 \%$ GBP 22 & $1.85(0.37-9$ & \\
\hline \multicolumn{3}{|l|}{$\geq 4$ sites with $P P D \geq 3.5 \mathrm{~mm} 23$} \\
\hline \multicolumn{3}{|l|}{$\geq 60 \%$ of sites with CAL $\geq 3 \mathrm{~mm} 24$} \\
\hline \multicolumn{3}{|l|}{$\geq 4$ sites with $C A L \geq 3 \mathrm{~mm}$ and $\mathrm{PPD} \geq 4 \mathrm{~mm} 25$} \\
\hline \multicolumn{3}{|l|}{$>5 \%$ sites with PPD $\geq 5 \mathrm{~mm}$ and $>5 \%$ sites with $\mathrm{CAL} \geq 3 \mathrm{~mm} 26$} \\
\hline \multicolumn{3}{|l|}{$\geq 4$ teeth with $\geq 1$ site with $C A L \geq 3 \mathrm{~mm}$ and $\mathrm{PPD} \geq 4 \mathrm{~mm}$ in the same site 27} \\
\hline \multicolumn{3}{|c|}{$\begin{array}{l}\text { Periodontal health: absence of PPD }>3 \mathrm{~mm} \text { and no site with CAL }>2 \mathrm{~mm} \text {, mild periodontitis, and } \\
\text { severe periodontitis } \geq 4 \text { sites with PPD } \geq 5 \mathrm{~mm} \text { and } C A L \geq 2 \mathrm{~mm} 28\end{array}$} \\
\hline \multicolumn{3}{|l|}{ Mean PPD, plaque index, GBP > median 29} \\
\hline \multicolumn{3}{|l|}{ No disease: $P P D<5 m m$, disease $\geq 1$ site PPD $\geq 5 \mathrm{~mm} 30$} \\
\hline \multicolumn{3}{|l|}{$\geq 6$ sites with $\mathrm{PPD} \geq 5 \mathrm{~mm}$ and $\geq 1$ site with $\mathrm{CAL} \geq 2 \mathrm{~mm} 31$} \\
\hline$\geq 1$ site with $\mathrm{PPD} \geq 5 \mathrm{~mm}$ and $\geq 2$ sites with $\mathrm{CAL}>6 \mathrm{~mm}$ and $\mathrm{GBP}>5 \% 32$ & $6(1.11-3.83)$ & $1.83(0.97-3.46)$ \\
\hline No disease: $<30 \%$ CAL $\geq 3$ severe disease: $\geq 30 \%$ CAL $\geq 3 \mathrm{~mm} 15$ & $2.40(1.20-4.78)$ & $1.79(0.86-3.69)$ \\
\hline Severe periodontal disease: $\geq 30 \% \mathrm{CAL} \geq 5 \mathrm{~mm} 12$ & $2.80(1.18-6.61)$ & $1.27(0.47-3.45)$ \\
\hline \multicolumn{3}{|l|}{ Proposed models } \\
\hline Definition $1: \geq 10 \%$ of sites with PPD $\geq 4 \mathrm{~mm}$ and $\mathrm{CAL} \geq 4 \mathrm{~mm}$ & $2.54(1.28-5.07)$ & $2.02(0.97-4.21)$ \\
\hline Definition $2: \geq 10 \%$ of sites with $P P D \geq 4 \mathrm{~mm}$ and $\mathrm{CAL} \geq 4 \mathrm{~mm}$ and $\mathrm{GBP} \geq 1$ & $2.23(1.11-4.50)$ & $1.97(0.96-4.06)$ \\
\hline Definition $3: \geq 20 \%$ of sites with $\mathrm{CAL} \geq 3 \mathrm{~mm}$ & $1.72(0.60-4.94)$ & $1.52(0.51-4.52)$ \\
\hline Definition $4: \geq 20 \%$ of sites with $C A L \geq 4 \mathrm{~mm}$ & $1.76(1.01-3.08)$ & $1.61(0.91-2.87)$ \\
\hline Definition $5: \geq 10 \%$ of sites with $\mathrm{CAL} \geq 4 \mathrm{~mm}$ & $3.44(1.58-7.51)$ & $2.56(1.12-5.88)$ \\
\hline
\end{tabular}

\section{CAL: clinical attachment level; GBP: gingival bleeding on probing; D: probing po depth.}

* Adjusted for gender, age, hypertension.

Table 6

Results of multiple logistic regression analysis, crude and adjusted a ratios (OR) with respective $95 \%$ confidence intervals $(95 \% \mathrm{Cl})$ for relationship between altered caroti artery intima-media complex (IMC) (dependent variable) and periodontal disease, age, gender, hypertension, diabetes and body mas ndex (BMI) (independent variables) for the best observed model (definition 5).

\begin{tabular}{|c|c|c|}
\hline Variable/Category & crude OR $(95 \% \mathrm{Cl})$ & Adjusted OR \\
\hline Age * & $1.06(1.03-1.10)$ & $1.04(1.01-1.08)$ \\
\hline \multicolumn{3}{|l|}{ Gender } \\
\hline Male & $1.98(1.13-3.47)$ & $1.78(0.97-3.27)$ \\
\hline \multicolumn{3}{|l|}{ Hypertension } \\
\hline Yes & $2.19(1.24-3.87)$ & $1.85(0.98-3.48)$ \\
\hline \multicolumn{3}{|l|}{ Diabetes } \\
\hline Yes & $2.39(1.04-5.47)$ & $1.34(0.55-3.25)$ \\
\hline & $3.44(1.58-7.51)$ & $2.56(1.12-5.88)$ \\
\hline & 1.00 & 1.00 \\
\hline & $1.44(0.76-2.72)$ & $1.51(0.76-2.97)$ \\
\hline & $2.05(0.94-4.45)$ & $2.05(0.87-4.85)$ \\
\hline
\end{tabular}

${ }^{*} \mathrm{p}<$

Nc. definition $5: \geq 10 \%$ of sites with clinical attachment level $(C A L) \geq 4 \mathrm{~mm}$. 
definitions that include PPD and bleeding are considered more robust, since CAL is known to be related to history and sequelae of periodontal disease.

Another limitation of this study is that only clinical measurements of periodontal disease were evaluated. Microbiological data and inflammatory markers for periodontal disease have been proven as more specific indicators 13,14 as compared to clinical parameters. The study also failed to measure such risk parameters for cardiovascular disease as C-reactive protein, cholesterol (LDL and HDL), and triglycerides.

A recent study reported the effect of periodontal treatment on changes in the carotid.
The observations indicated that cha es in ${ }^{\top} \mathrm{IC}$ thickness after periodontal treatment possible in systemically healthy individuals 9 . Fu re intervention studies are necescary to better char acterize the role of periodonta. 'isease an ${ }^{\prime}$ its products on clinical and suhclinica ard vascular events.

Based on the curr ht study's - adings, we conclude that differen measurem its for the severity of period $t a l$ ase ar number of teeth were asso atea th carotid thickness. In addition, indi duals with $\%$ or more sites with CAL $\geq 4 \mathrm{~mm}$, ved higher odds of altered carotid thick ess afto ontrolling for confounding factors.

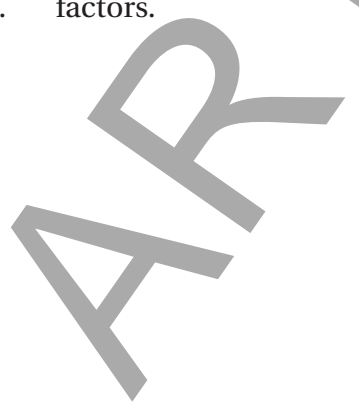

\section{Resumo}
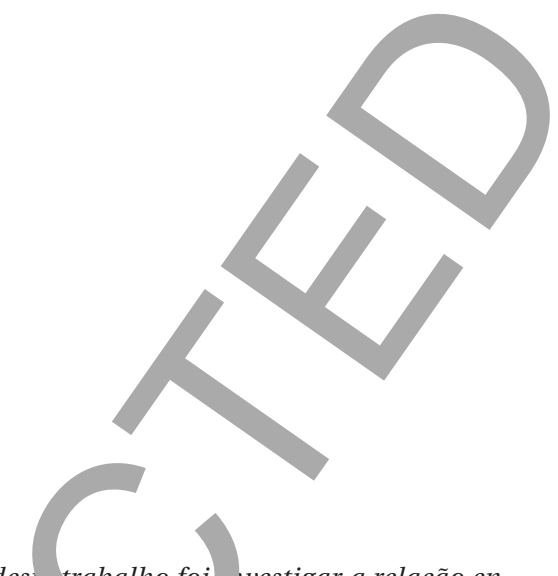

O objetivo desi trabalho foi vestigar a relação entre doença perio. "tal e a e eração da espessura do complexo médio-inu. a carótida. Foi conduzido um es ronal com 220 indivíduos (idade $\geq 35$ anos) pa icipa es... Zstudo Longitudinal de Saúde do Adulto $\checkmark$ A-Brasil). Foram realizados ultrassoafia da téria carótida e exame clínico periodont que in iu índice de placa visível, índice de sang $\ldots$ à sondagem, profundidade de bolsa à son igem ( $\left.P_{D} S\right)$ e nível clínico de inserção (NCI). Indiuos com espessura da carótida com alteração tiveram. onos dentes presentes, maior frequência de NCI $\geq 3 \mathrm{~mm}, \mathrm{NCI} \geq 4 \mathrm{~mm}, \mathrm{NCI} \geq 5 \mathrm{~mm}$ e $N C I \geq 6 \mathrm{~mm}$ e $P B S$ $\geq 4 \mathrm{~mm}$ em comparação com aqueles sem alteração ( $p$

0,05). Apesar de usadas 17 definições para a doença periodontal, apenas uma confirmou a hipótese de associação entre a doença periodontal e a aterosclerose subclínica. Indivíduos com 10\% ou mais dos sítios com $N C I \geq 4 m m$ tiveram maior chance de apresentar espessamento de carótida.

Aterosclerose; Doença das Artérias Carótidas; Periodontia

\section{Contributors}

R. M. Batista participated in the study conceptualization and design, data collection, analysis, and interpretation, and writing of the article and was responsible for the study as a whole. E. P. Rosetti collaborated in the study conceptualization and design, data analysis and interpretation, writing of the article, critical revision of the text, and final approval of the article. E. Zandonade contributed to the study conceptualization and design, data analysis and interpretation, statistical analysis, writing of the article, critical revision of the text, and final approval. L. H. Roelke participated in the data collection and critical revision of the text. M. V. Vettore contributed to the data analysis and interpretation and critical revision of the text. A. E. Oliveira collaborated in the study conceptualization and design, writing of the article, and critical revision of the text. 


\section{References}

1. Departamento de Análise de Situação em Saúde, Secretaria de Vigilância em Saúde, Ministério da Saúde. Saúde Brasil 2007: uma análise da situação de saúde. Brasília: Ministério da Saúde; 2007. (Série G. Estatística e Informação em Saúde).

2. Greenland P, Knoll MD, Stamler J, Neaton JD, Dyer AR, Garside DB, et al. Major risk factors as antecedents of fatal and nonfatal coronary heart disease events. JAMA 2003; 290:891-7.

3. Franek E, Blaschyk R, Kolonko A, Mazur-Psonka L, Langowska-Adamczyk H, Kokot F, et al. Chronic periodontitis in hemodialysis patients with chronic kidney disease is associated with elevated serum C-reactive protein concentration and greater intima-media thickness of the carotid artery. J Nephrol 2006; 19:346-51.

4. Demmer RT, Kocher T, Schwanhn C, Volzke H, Jacobs DR, Desvarieux M. Refining exposure definitions for studies of periodontal disease and systemic disease associations. Community Dent Oral Epidemiol 2008; 36:493-502.

5. Cairo F, Castellani S, Gori AM, Nieri M, Baldelli G, Abbate R, et al. Severe periodontitis in young adults is associated with sub-clinical atherosclerosis. J Clin Periodontol 2008; 35:465-72.

6. Söder PO, Meurman JH, Jogestrand T, Nowak J, Söder B. Matrix metalloproteinase- 9 and tissue inhibitor of matrix metalloproteinase-1 in blood as markers for early atherosclerosis in subjects with chronic periodontitis. J Periodontal Res 2009; 44:452-8.

7. Cortelli JR, Lotufo RFM, Oppermann RV, Sallum AW. Glossário da Sociedade Brasileira de Periodontologia. São Paulo: Sociedade Brasileira de Periodontologia; 2005.

8. Mustapha IZ, Debrey S, Oladubu M, Ugarte R. Mar ers of systemic bacterial exposure in periodo al disease and cardiovascular disease risk: a sy en atic review and meta-analysis. J Periodont 2007; 78:2289-302

9. Piconi S, Trabattoni D, Luraghi C, Per L, Borelli M, Pacei M, et al. Treatment of perio ontal diseas results in improvements in endothel dysfunction and reduction of the carotid intima- edia thickness. FASEB J 2009; 23:1196-204.

10. Dyke TEV. Inflammation and indontal diseases: a reappraisal. J Periodontol 200 79:15u,

11. Tzorbatzoglou ID, Sfyroeras $G$ Gi noukas AD. Periodontitis and carotid atherom there a causal relationship? Int Ang $29: 27$ -

12. Burt B; Research, $c$ lence ac Therap Committee of the American cademy if Per jntology. Position paper: epiden. Periodontol 05; 76:14 19.

13. Desvarieu 1, Demmer RT, ndek T, Boden-Albala B, Jacob ,r. L Papapanou PN, et al. Periodontal microbıta and ca id intima-media thickness: the Oral Afections and Va ular Disease Epidemiology St $y$ (INVFST). Circulation 2005; 111:576-82.

14. ck JD, e P, Heiss G, Madianos P, Couper D, Lin $+\mathrm{al}$ eriodor i disease and coronary heart disease. eappra al of the exposure. Circulation 2005; $12: 19-2$
15. Beck JD, Elter JR, Heiss G, Couper D, Mauriello SM, Offenbacher S. Relationship of periodontal disease to carotid artery intima-media wall thickness: the atherosclerosis risk in communities (ARIC) study. Arterioscler Thromb Vasc Biol 2001; 21:1816-22.

16. Desvarieux M, Demmer RT, Rundek T, Bodenbala, Jacobs DR, Papapanou PN, et al. Relations ip between periodontal disease, tooth loss, and carc d artery plaque: the Oral Infections and Vasc lar Dis ease Epidemiology Study (INVEST). Strokt $\cap 3$; 34:2120-5.

17. Scannapieco FA, Bush RB, Paju S. Ac ciations between periodontal disease and risk $r$ a rosclerosis, cardiovascular disease and st. $\mathrm{ke}$ : a syo natic review. Ann Periodontol 2003; 8·28-53.

18. Xiang $X$, Sowa MG, Iacopino $a v 1$, ev RG, Hewko MD, Man A, et al. An upde on nor n-invasive approaches for periodon diagn s. J Pe. dontol 2010; 81:186-98.

19. Ainamo J, Bay I. Problems and ps osals for recording gingivitis and $r$ Int Dent J 5 ; 25:229-35.

20. Stein JH, Korcarz C Hüs nn E, Kendall CB, Mohler ER, et al. Use cca tid ultrasound to identify subclinical vascular ease and evaluate cardiovascular disease risk: a c sensus statement from the American Society of Ec ocardiography Carotid Intim the Thickness Task Force. Endorsed by the c ciety for Va ular Medicine. J Am Soc Echocardi 2008; 21:93-1.

21. Minıs io da Saú e. Orientações para a coleta e análise au 'do antropométricos em serviços de saúd Brasíllà Ministério da Saúde; 2008.

22. Ra ai M, Gorzó I, Nergy E, Urbán E, Novák T, Pál A. $f$ possible ssociation between preterm birth and rly pe odontitis. Pilot study. J Clin Periodontol $20 \mathrm{u} .736-41$.

23. Lunardelli AN, Peres MA. Is there an association between periodontal disease, prematurity and low irth weight? A population-based study. J Clin Periodontol 2005; 32:938-46.

24. Offenbacher S, Katz V, Fertik G, Collins J, Boyd D, Maynor G, et al. Periodontal infection as a possible risk factor for preterm low birth weight. J Periodontol 1996; 67:1103-13.

25. Moliterno LFM, Monteiro B, Figueredo CMS, Fischer RG. Association between periodontitis and low birth weight: a case-control study. J Clin Periodontol 2005; 32:886-90.

26. Moore S, Ide M, Coward PY, Randhawla M, Borkowska E, Baylis R, et al. A prospective study to investigate the relationship between periodontal disease and adverse pregnancy outcome. Br Dent J 2004; 197:251-8.

27. Lopez NJ, Smith PC, Gutierrez J. Periodontal therapy may reduce the risk of preterm low birth weight in women with periodontal disease: a randomized controlled trial. J Periodontol 2002; 73:911-24.

28. Offenbacher S, Lieff S, Boggess KA, Murtha AP, Madianos PN, Champagne CM, et al. Maternal periodontitis and prematurity. Part I: obstetric outcome of prematurity and growth restriction. Ann Periodontol 2001; 6:164-74. 
29. Rajapakse PS, Nagarathne M, Chandrasekra KB, Dasanayake AP. Periodontal disease and prematurity among nonsmoking Sri Lankan women. J Dent Res 2005; 84:274-7.

30. Geerts SO, Legrand V, Charpentier J, Albert A, Rompen EH. Further evidence of the association between periodontal conditions and coronary artery disease. J Periodontol 2004; 75:1274-80.

31. Fisher MA, Borgnakke WS, Taylor GW. Periodontal disease as a risk marker in coronary heart disease and chronic kidney disease. Curr Opin Nephrol Hypertens 2010; 19:519-26.
32. Marin C, Segura EJJ, Martinéz AS, Bul 4P. Cor ation between infant birth weight and mo ${ }^{\prime}$ ' periodontal status. J Clin Periodontol 2005; 32:29. $\urcorner 4$.

33. Mochari H, Grbic JT, Mosca L. Usefulness of su reported periodontal disease $:$ dentify individuals with elevated inflammatory marn at risk o car-

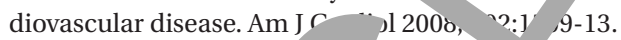

34. Genctoy G, Ozbek M, Ar a N, Kahraman S, arkpantur A, Yilmaz R, et al. ( hgival health atus in renal transplant recipients: 1 ationship bet een systemic inflammation ?nd ath sclerosis it J Clin Pract 2007; 61:577-82.

Submitted $123 / \mathrm{Jul} / 2011$

Final ver on ubmitted on 24/Jan/2012

Approvid on 26/, /2012

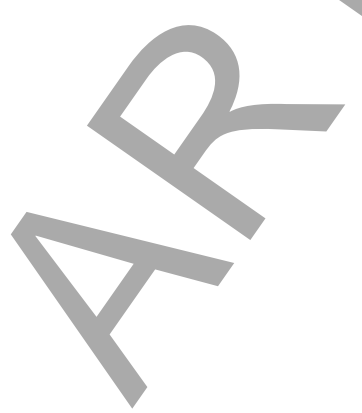

